\title{
Case study, scenarios and the exploration of humans' subjectivity for market-based instrument success: an integrated framework
}

\author{
G. L. Kerr ${ }^{1}$ \& H. Bjornlund ${ }^{2,3}$ \\ ${ }^{1}$ University of Calgary, Alberta, Canada \\ ${ }^{2}$ University of Lethbridge, Alberta, Canada \\ ${ }^{3}$ University of South Australia, Australia
}

\begin{abstract}
Societies are dependent on healthy aquatic ecosystems to supply crucial ecosystem services for human well-being; including quality source water for drinking, economic use and recreational opportunities. Non point source (NPS) contamination of water in southern Alberta's agricultural belt is an issue despite legislation and policy. Market-based instruments are promoted in Alberta as a tool to help meet environmental management goals; however there is little experience with their effective design and implementation. This paper proposes an integrated methodological framework to be layered on the economic principles of MBIs to increase the likelihood of their success. The framework integrates a case study method with a relevant and realistic MBI scenario that is then tested for legitimacy and acceptance of the tool using Q method. It is assumed that human subjectivity plays a significant role in trade-off choices that individuals and groups make generally and in particular with regard to the environment. Subjectivity, context and institutional structures can play a significant role in the adoption/ success or failure of management tools for environmental issues.
\end{abstract}

Keywords: ecosystem services, integrated framework, water quality, market-based instruments, $Q$ method.

\section{Introduction}

Society is dependent on healthy aquatic ecosystems to supply crucial ecosystem services (ES) for human well-being; including quality source water for drinking, 
economic use and recreational opportunities. Presently human development activities are threatening many ecosystems and thereby the quality of life of our societies.

Most aquatic ES management problems defy traditional bureaucratic and analytic approaches to problem solving because they are 'wicked'; i.e. they are complex, non-linear and contain uncertainty [1]. Traditional solutions, such as uniform standards, lack the flexibility to adapt under these circumstances. Market-based instruments (MBIs) have become more and more popular as they are flexible tools that can reduce costs of meeting the environmental objective and can increase innovation and experimentation in new technologies [2]. Within the province of Alberta, Canada, MBIs have recently been considered as a governance tool to incent a change in the degradation of ecosystems and the critical services they provide.

Case studies of modern 'wicked' environmental issues have exposed the interrelationship between the environment and humans, coined the socialecological system (SES) [1]. The emergence of SES requires a change in both how we understand the issues and how we solve them. Environmental issues, such as water quality, need to be placed into the appropriate context and need to integrate the relevant stakeholders into both the understanding of the issue and as the primary sources of solutions. This shift in both understanding of and how to solve complex problems requires a new framework.

This paper explores the development of an integrated methodological framework that builds on strong economic principles and rules for MBI design to maximise the success of an MBI in a given context. It is proposed that the application of the integrated framework can overcome some of the weaknesses or limitations of current MBI design and can assist governments in successfully implementing flexible MBIs to meet the desired objectives.

The next sections provide an overview of MBIs for ecosystem objectives, the presentation of the integrated methodological framework, an application within southern Alberta and final conclusions and recommendations.

\section{Market-based instruments}

Laws and policies to secure environmental outcomes often fail to achieve their objectives [3]. Even with water quality regulations and policies in place, southern Alberta still experiences water quality below acceptable levels, particularly in the Battersea Drain Area (BDA) (See Figure 1). Economists argue that this is partly because aquatic ecosystems are perceived by decisionmakers and users as having little value because it is difficult to express or measure that value or contribution in a meaningful way. For instance the water filtration services provided by rivers may be significant to a particular community but there are few meaningful ways to express this value. Additionally it is difficult to define a change in supply of ES resulting from specific actions, due to scientific uncertainty or poor measurements of baseline conditions [2]. 


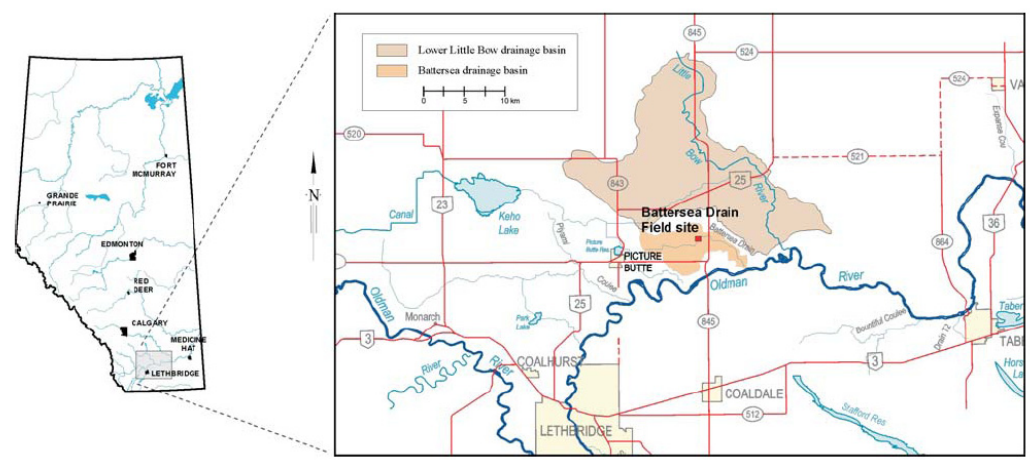

Figure 1: $\quad$ Battersea drain area in Southern Alberta (reproduced from [4]).

Market-based instruments establish a value where none exists; which presents an opportunity for governments to articulate the importance of the ES provided by the ecosystem, such as water filtration from rivers. The value of ES could then be considered in decisions taken and actions made by governments or other actors. This may have been one of the reasons why Alberta promotes MBIs as new governance tools to help dealing with ecosystem degradation within its Water for Life Strategy and Land-Use Framework [5, 6].

Market-based instruments incent 'rational man' with price signals to adopt desired behaviour or penalties for continuing poor behaviour [2]. Some of the key strengths of MBIs, both theoretically and from case study observations are that they are more flexible and efficient than traditional tools such as universal standards, and can internalize some of the costs or benefits that are outside the current decision-making context. One of the other benefits of MBIs is that they allow each participant to make their own choices about how much they want to engage in an MBI based on their privately held information, such as costs and, for instance, preferences, attitudes and beliefs and their own particular circumstance, such as succession plans for their farms [7].

The strengths of MBIs are countered by a number of weaknesses. Two significant weaknesses are the inability to fully/properly incorporate equity and legitimacy issues associated with MBIs. Markets are not typically designed to incorporate equity and therefore are criticized for their distributional impacts and therefore some people argue that they are not an appropriate tool for dealing with complex and important environmental issues that impact communities [7]. There are also a number of barriers to implementation that are important to consider upfront.

A lack understanding and incorporation of social context has hampered MBI success and while context will be more broadly covered in the next section, this lack of contextual understanding leads to such issues as a lack of trust and legitimacy it is argued. Some the MBIs for environmental purposes are also looked at as 'immoral', for example there has been a large backlash in developing some Payment for Ecosystem Services programs as there is a 
perception that farmers shouldn't be paid for activities they are morally obligated to do on their lands. Others believe that governments should be accountable and responsible for the management of ES and the environment, and should use regulation and rules in that process [8].

The design of MBIs follows a fairly well documented set of economic principles and as such this paper will not go into the design but will build on it. Neo-classical economists have long maintained that farmers will make choices based on rational economic assumptions, but this is now being questioned in light of the realisation that there are many factors that impact farmers' decisionmaking. Among these factors are attitudes towards the policy issue at hand [9].

Recent research has shown that peoples' perception of environmental issues and which policies should be used to resolve them are case specific, which means it depends on the issue as well as the local context [10]. It has therefore been argued that for governments to successfully employ MBIs as a governance tool their design and implementation must be fitted to meet the context or 'story' of the place and people in which it is to be applied [8]. Once the 'story' has been developed it is possible to assess not only what category of MBI might apply but also to tease out what particular type would be most likely to succeed within that context and institutional arrangements. The next section presents an integrated framework proposed to assess an MBI design process.

\section{Methodology: case study scenario and $Q$ method - a novel mix}

In social science research, a multi method approach using qualitative and quantitative data is recommended to shed light on the perceptions and value orientations of the subject group [11]. This paper proposes to apply an integrated framework, using qualitative and quantitative data, to assess if an MBI will 'fit' within a specific context and be accepted by key stakeholder groups.

The framework has three components; the development of a place-based case study, the layering of a 'best fit' scenario for an MBI and application of a Q sort. The purpose of the Q sort (explained in next section) is to test the scenario with key stakeholders to see if the values and perspectives of the actors match with what is proposed. This will provide a novel lens to gain insights about some of the acceptability and legitimacy issues or opportunities to incorporate into the MBI design and implementation. Ultimately, it is proposed that this integration of economic design with the integrated framework will increase the chances of the MBI being a successful tool to meet complex environmental objectives.

\subsection{A case study scenario}

Case study research starts from the desire to provide an up-close and in-depth understanding on a single case set into its real world context. This 'closeness' aims to produce an invaluable and deep understanding that results in new learning about real-world behaviour and its meaning. This case study research 
assumes that examining the context and other complex conditions related to the case are integral to understanding it as a whole versus a set of isolated variables.

In the context of an MBI, there are two facets of context that can play a critical role in the successful implementation of an MBI; the first is the context of place and the second is the social values and norms held by the actors [11]. The process of building the case, including the institutional arrangements, is critical to understand the opportunities and risks of developing and implementing a new governance tool in the certain place. These arrangements are critical for a government to analyse to ensure the technical fit of an MBI.

The context of social values can be partially explored in the case study development through the evidence of social perspective, or subjectivity, elicited in the literature and interviews. Subjectivity is conceived as the internal reference frame that a person calls upon to understand the world. Measuring subjectivity then requires responses to be collected in the moment when a participant is expressing a viewpoint on an actual issue [12]. Q method is then recommended to provide a unique and deeper level of social context by exploring the subjective perspectives and values for an issue in the moment that it is occurring.

\subsubsection{Context and institutional arrangements}

Grafting new governance tools onto existing arrangements is generally impossible due to a number of issues including context and institutional fit [11]. Further, when the new approach does not match the context, legitimacy and accountability are called to question by affected stakeholders.

"Prescriptions need to fit contexts" [8]. Context is the complex characteristics that distinguish one geographic and temporal place from another. Understanding, or building, the context in a SES provides the basis on which to comprehend and approach the complex, non-linear dynamics [3]. Context signifies the nexus of physical, natural, political, cultural, social, and economic phenomena that make one place distinct from another. Part of understanding and building the context for MBIs is to characterize the institutional arrangements. Institutions are defined as the "rules" in any kind of social structure, i.e. the laws, regulations and their enforcement, agreements and procedures [11].

Organisations are a particular type of institution and are composed of groups of people with a common objective. Organisations can be formalised, such as "official" sector organisations with operational objectives, their own budget and professional staff (such as government ministries, irrigation districts or consultants) or they can be informal and less well described (such as "the public", volunteers associated by a theme or the socio-economic distinct groups in a county or town) [13].

The literature suggests that these acceptance issues are heavily impacted by the context and institutional arrangements and differ between the suppliers, buyers, and community levels [8, 14]. Institutional arrangements are common enabling conditions for governance tools and therefore should be specifically developed within the MBI [11]. 


\subsection{Scenario development}

Scenarios are the carefully constructed stories about the future and the potential paths to it, although there are a number of different definitions in the literature. For the purposes of this framework design, the scenario approach is used as a forecasting tool to assess the likely success of a specific MBI tool to meet a set management objective. The process is therefore designed to assist a government trying to successfully use a MBI, with little experience with the design and implementation of them.

The use of an exploratory scenario allows one to start from the past to the present and then to layer on a potential realistic future and the likely steps toward it [15]. The scenario, therefore, provides a space to present and test some of the acceptability issues of a governance tool. In the case of understanding or building acceptability for MBIs, we look to include descriptions, events, actors (people) and mechanisms to describe one possible path that the SES could take.

This scenario approach uses the raw information obtained in the process of building the case study (interviews, literature searches, institutional analysis, context building) to focus in on a specific issue of aquatic ecosystem management, such as water quality contamination from non-point source pollution (NPS), to which an MBI would be a potentially applicable tool (i.e. meets the traditional economic criteria). The next step in the scenario would be to define which categories of MBIs would be most likely to apply within the given context and issue (i.e. quantity based instruments with a defined property right or price based instruments such as a charge or subsidy). Last a tool would be designed for the specific issue. Section 4 will provide a design example.

\subsection{Q methodology}

Within the literature, the extent to which community members accept MBIs for the provision of ES is not well documented. Community member perceptions and knowledge about MBIs may significantly affect the effectiveness of MBIs as a tool for enhancement of ES [14]. To understand the acceptability issues of individuals and stakeholder groups there is a need to dig deeper into the subjectivity that individuals hold. The Q method, developed in the 1930's by the psychologist William Stephenson, is a method for studying the subjective beliefs and attitudes of individuals. Specifically, Q method can be used in the policy process to examine what factors have influenced decision-making in the past, to better understand how future decisions may be influenced by the perspectives of stakeholders and decision makers, and to facilitate the search for compromise solutions to difficult policy issues.

To elicit these values and perspectives $Q$ provides an inductive, yet systematic way of assessing the values of subgroups of actors. In $\mathrm{Q}$ method one can uncover the subjective values or perspectives in a debate or on an issue without imposing predefined categories, such as is often done in conventional survey methods. Once the Q sorts are completed and analyzed the results are a range of different value orientations based on correlations of individual patterns of belief, expressing the subjective perspectives of each actor [12]. 
The Q method starts by selecting a sample of representative statements, from all key perspectives, about an issue of interest. These statements will come from interviews, literature reviews and context evidence from the place. Next Q sorts will be performed by a limited number of participants that represent the key stakeholder perspectives. The participants will sort all of the perspectives on a most agree to least agree spectrum. The results will be analyzed using factor analysis techniques to generate the key perspectives or factors and to show the breadth and depth of the perspectives.

Over the past decade, Q method has become an increasingly popular method for exploring decision-making and public policy and to investigate stakeholder attitudes towards a range of important agricultural policy issues, including water pollution. The next section provides an example of how the authors intend to apply this framework to a MBI developed for NPS water quality issue in southern Alberta.

\section{Next steps: case application to test theoretical contributions}

In this study the context is water pollution from non-point agricultural sources within the Battersea Drain area in Southern Alberta. This is an area with intensive farming, irrigation and husbandry experiencing water quality problems.

\subsection{The Alberta context - MBIs and water quality issue}

The southern region of Alberta suffers from severe impacts on its aquatic ecosystems. In 2003, the Alberta Government undertook studies to understand aquatic ecosystem needs in order to inform the South Saskatchewan River Basin (SSRB) planning process. One study rated 31 of 33 main stem rivers in the SSRB as either 'moderately impacted' to 'degraded' as a consequence of the current level of water extraction [16].

Agriculture is the largest source of non-point source (NPS) contamination in southern Alberta. While point source contamination is regulated and managed the mandate and responsibility for dealing with NPS water quality issues appears unclear and overlapping. Livestock production is a major component of the agricultural industry in Alberta, accounting for the largest number of cattle and calves in Canada [17]. The focus on livestock production has come at a cost. Water quality monitoring in tributaries of the Oldman River has shown total Phosphorous and total Nitrogen concentrations in excess of the Alberta Surface Water Quality Guidelines, and levels of faecal coliforms that occasionally exceed provincial guidelines for contact recreation and irrigation [4, 18].

Livestock production is considered a primary source of phosphorous $(\mathrm{P})$ in the environment and manure spreading when improperly managed can be an excess source of $\mathrm{P}$ into surface waters. In the longer term repeated application of manure and commercial fertiliser can result in a build-up in the soil as more $\mathrm{P}$ is available than plants can absorb [18].

Market-based instruments are being promoted in Alberta to augment traditional governance tools for the management of complex and scientifically 
uncertain nature of environmental issues, such as water quality contamination. In Alberta a number of policies and legislation has been introduced to enable and encourage the use of MBIs. These include: the Water for Life Strategy (WFL) [5]); the Land-Use Framework (LUF); the Alberta Land Stewardship Act (ALSA) [6] and others. The Alberta government's approach of broadly encouraging MBIs for environmental policy is problematic given the limited experience with MBIs and lack of evidence of their acceptability in Alberta.

\subsection{Battersea drainage area}

In Alberta the focus of agricultural impacts has been on livestock production and in particular intensive livestock industry and related manure management issues. [19]. Within the BDA this issue has resulted in an inability to use the water for drinking and some can not use it even for stock watering because of the low quality.

\subsubsection{Community context}

The Battersea Drainage Area (BDA) is characterized geographically as a small sub-basin, shown in Figure 1. The population of BDA is primarily first and second generation Dutch immigrant farmers carrying out intensive livestock operations. Within the BDA there is a small and homogenous group of land owners that know each other (crops and intensive livestock). There is a high level of social capital within the community, emphasized by the commitment to a number of volunteer efforts to deal with environmental issues within in the BDA such as the BDA Water Quality Initiative (BDAWQI). Geographically the BDA is located within the South Saskatchewan River Basin (SSRB) and the South Saskatchewan Regional Plan (SSRP) area.

\subsubsection{Issue context}

The Battersea Drainage Area, in Southern Alberta, was selected for a case study as there is a clear and well recognized water quality issue caused by non-point source nutrient run-off $[4,18]$. The BDA has one of the most dense livestock populations in North America; it is part of what is commonly known as Canada's feedlot alley. It has, as a result of the intensity and the small size of its subbasin, therefore had continued water quality issues from the NPS contribution of manure and fertilizer application. There appears to be no political will to force a reduction in the number of livestock per acre, even though it is not meeting WQ guidelines for $\mathrm{N}$ and $\mathrm{P}$ and ultimately drains into the Oldman River. Within the BDA there has been a focus on water quality, particularly on nutrients and coliform bacteria. Nutrients, such as nitrogen and phosphorus are essential for crop growth; however, even very small amounts in water can cause eutrophication, oxygen depletion, and taste and odour problems (ORBWQI, 1999). The BDA has historically had significant water quality issues.

\subsubsection{Institutional arrangements}

The BDA is nested within a number of formal governance institutions. Legislatively the $\mathrm{BDA}$ is subject to a number of Acts and regulations, including 
the Water Act, Environmental Protection and Enhancement Act, the Agricultural Operational Practices Act and a number of regulations and guidelines administered by Natural Resources and Conservation Board (NRCB), Alberta Agriculture and Rural Development and Alberta Environment. From a planning perspective there is the Approved South Saskatchewan River Basin Water Management Plan that acts at a larger regional scale [16]. At a sub watershed scale the BDA is part of the Oldman River WPAC and the Lethbridge Northern Irrigation District.

Within the Oldman River Watershed there is also an informal set of governance institutions with respect to water quality, regulation and supply. The Oldman Watershed Council (OWC) was formed in 2004 with a mission to maintain and improve the Oldman River Watershed through partnerships, knowledge, such as State of the Watershed reporting, and implementation and integration of sustainable water management and land use practices. The OWC was formed by bringing together two former groups operating in the area; the Oldman River Basin Water Quality Initiative (ORBWGI) and the Oldman Basin Council both of which were actively working on water quality solutions.

At a local level the BDA has had a voluntary BDA Water Quality Initiative (BDAWQI) for about 10 years working on building a better understanding of and solutions for the water quality issues in the BDA. The BDAWQI is run through the BDA Working Group (BDWG) and it describes itself as an informal group of agricultural producers that live and work within the Battersea Drain Watershed with the purpose of minimizing the impacts of agricultural practices on water quality in the Battersea Drain and Oldman River. The BDWG's work is primarily to promote and implement Best Management Practices to improve water quality, a common theme of a number of groups in this area. There has been some success in the uptake of these BMPs; however research is still ongoing [18]. The long term commitment of the community through the BDAWQI and participation on the WPAC demonstrates the significance of the issue to the community.

\subsubsection{MBI focus in the BDA: a manure tool}

Even with the formal and informal governance structures manure management is an issue for farmers in the BDA and for southern Alberta in general. As water quality is an immediate and longer term issue within the BDA and that manure run-off is a key contributing factor [18], there is an immediate opportunity to build and test a directional incentive; that is an MBI that modifies behaviour over time, to shift the trend in the BDA.

The nature of intensive livestock coupled with the near complete containment in the drain creates an excess supply of manure. Presently the NRCB rules for manure application, and the high cost of transporting the manure out of the area are the biggest challenges to the farmers. There have been a number of ideas expressed at various meetings and forums. A focus on manure resonates with most farm audiences; specifically with either a market for manure compost or a manure-to-fuel program that provides a local solution and produces an economically viable alternative. 
The composting option has gained more recent popularity as a management option amongst the BDA community. Composting reduces the volume of manure. On a province-wide basis, there is adequate cropland area to make use of all the nutrients available in the manure produced. However, manure production tends to be concentrated on smaller land areas, such as the BDA. Benefits of manure are constrained by both hauling costs and the costs of managing the manure itself.

\subsection{Q sort}

For this case the Q statements, or concourse, will be focused around issues of acceptance and fit, in the use of a manure management MBI to address NPS water quality in the BDA. The Q sort will contain a set of statements drawn from the context building exercise, interviews, and observations to ensure that all the major perspectives on the issue are recognized and presented. For instance there are perceptions about the rights and responsibilities of agricultural actors that should be exposed to highlight potential areas of friction on MBI implementation. A Q sort statement could then be, for example "Agricultural landowners are accountable to clean up any environmental issues they cause because of their practices".

Participants will be recruited from the case study area. In this case the stakeholder groups being targeted for interviews and the $\mathrm{Q}$ sort include: agricultural, government (municipal, provincial, federal), environmental groups, academic/ research community, and local land owners (non-ag) to ensure that the full suite of perspectives on the implementation of a manure management MBI are captured so to expose the key factors to both consider and inform governments implementation of MBIs.

Once the Q sorts are complete factor analysis will be applied to draw out significant factors within sub-groups. The factors provide a statistically significant result by how they load. The factors are then interpreted based on the content of the Q sort and the relationship among the statements. In this case we may find a factor group that prefers a beneficiary pay perspective to the water quality issues and another that loads toward a polluter pay perspective for managing the issue.

\section{Anticipated results and conclusions}

There are no easy fixes to the wicked environmental issues of today. The degradation of key ES has propelled governments to look for new or additional governance tools to help 'fix' the problems. MBIs are a potential solution that has gained significant support with the Government of Alberta in recent years; however MBIs won't simply work because a government designs and implements them based on economic principles alone.

This paper presents an integrated methods approach to build on economic principles and theory for good MBI design while also considering the context and social values of the area. The framework takes advantage of $\mathrm{Q}$ method to 
establish the variety of viewpoints people have in their use and care of the natural environment. By using the practical and analytical advantages of $\mathrm{Q}$ method the hope is to gain better insight into stakeholder views that can be proactively considered and used to refine or direct MBI design and implementation, ultimately bringing facts and values together in one story.

It is anticipated this framework can be used as a planning tool by government. The integrated MBI vetting framework described within this article provides governments struggling to use MBIs to enhance environmental management with a contextual and subjectivity lens to add to the traditional economic tool design criteria.

\section{Acknowledgement}

Funding for this research has been partially provided by the Canadian Water Network and Alberta Innovates.

\section{References}

[1] Folke, C., Carpenter, S., Walker, B., Schffer, M., Elmqvist, T., Gunderson, L., and Holling, C.S. Regime Shifts, Resilience and Biodiversity in Ecosystem Management. Annual Review of Ecological Evolution Systems 35, pp. 557-81, 2004.

[2] Anderson, J., Gomez W., C., McCarney, G., Adamowicz, W., Chalifour, N., Weber, M., Elgie, S., and Howlett, M Ecosystem service valuation, market-based instruments and sustainable forest management: a primer. State of Knowledge primer. Sustainable Forest Management Network, Edmonton, Alberta. 25 pp. 2010.

[3] Poirier, Assessing Institutions For Aquatic Ecosystem Protection: A Case Study Of The Oldman River Basin, Alberta. Doctorate of Philosophy Thesis. 2008.

[4] Oldman River Basin Water Quality Initiative. Progress summary report. 2000.

[5] Alberta Water Council. Alberta Water for Life Strategy, Alberta Online. http://www.waterforlife.gov.ab.ca

[6] Alberta Government. Land-use Framework. Online. www.landuse.alberta.ca/ documents/Final_Land_use_Framework.pdf

[7] Landscape Change Team, Ecosystem Services through Land Stewardship Practices: Issues and Options. Land Management Group. Department of Sustainability and Environment. Victoria Australia, 2003.

[8] Ingram, H., Water as a multi-dimensional value: implications for participation and transparency. International Environmental Agreements. 6(420), p.3, 2006.

[9] Bjornlund, H., Efficient water market mechanisms to cope with water scarcity. International Journal of Water Resources Development. 19(4), pp. 553-567. 2003. 
[10] Clement, J. and Cheng, A. Using analyses of public value orientations, attitudes and preferences to inform national forest planning in Colorado and Wyoming. Applied Geography 31, pp. 393-400. 2011.

[11] Baird, J., Belcher, K. and Quinn, M.S., A Performance-Based Approach to Agri-Environmental Policy in Canada: Development and Comparative Analysis. Linking Environment and Agricultural Research Network: Research Project Nu: PR-02-2011. 2011.

[12] Vugteveen, P, Lenders, J.R., Stakeholder Value Orientations in Water Management. Society and Natural Resources, 23(1), p.3, 2010.

[13] Alaerts, G.J, F.J.A. Hartvelt and F.-M. Patorni (eds.). Water Sector Capacity Building: Concepts and Instruments. A.A. Balkema Publ., Rotterdam/Brookfield, VT. 1999.

[14] Bjornlund, H.; Nicol, L. and Klein, K. Challenges in Implementing Economic Instruments to Manage Irrigation Water on Farms in Southern Alberta. Journal of Agricultural Water Management 92, pp. 131-141, 2007.

[15] Michel Godet and Fabrice Roubelat, 1996. Creating the Future: The Use and Misuse of Scenarios. Long Range Planning, 29 (20, pp. 164 to 171, 1996.

[16] Alberta Environment, Approved Water Management Plan for the South Saskatchewan River Basin in Alberta. Edmonton: Alberta Environment, 2006.

[17] Johnson, J.Y.M, Thomas, J.E., Graham, T.A., Townshend, I., Byrne, J., Selinger, L.B., and Gannon, V.P.J. Prevalence of Escherichia coli O157:H7 and Salmonella spp. in surface waters of southern Alberta and its relation to manure sources. Canadian Journal of Microbiology, 49, pp. 326-335, 2003.

[18] Agriculture and Agri-Food Canada, Watershed Evaluation of Beneficial Management Practices (WEBs) partners. Retrieved from http://www4.agr.gc.ca/AAFC-AAC/displayafficher.do?id=1228498920881\&lang=eng, 2008

[19] Olson, B.M., and Kalischuk, A.R. (eds.). Nutrient beneficial management practices evaluation project 2007 to 2011: 2008 Progress report. Alberta Agriculture and Rural Development, Lethbridge, Alberta, Canada. pp. 344. 2009. 